\title{
Brief Pain Inventory-Facial minimum clinically important difference
}

\author{
Sukhmeet K. Sandhu, BA, ${ }^{1}$ Casey H. Halpern, MD, ${ }^{1}$ Venus Vakhshori, BS, ${ }^{1}$ \\ Keyvan Mirsaeedi-Farahani, BS, ${ }^{1}$ John T. Farrar, MD, PhD, ${ }^{2}$ and John Y. K. Lee, MD${ }^{1}$
}

Departments of ${ }^{1}$ Neurosurgery and ${ }^{2}$ Biostatistics and Epidemiology, University of Pennsylvania, Philadelphia, Pennsylvania

OBJECT Neurosurgeons are frequently the primary physicians measuring pain relief in patients with trigeminal neuralgia (TN). Unfortunately, the measurement of pain can be complex. The Brief Pain Inventory-Facial (BPI-Facial) is a reliable and validated multidimensional tool that consists of 18 questions. It measures 3 domains of pain: 1) pain intensity (worst and average pain intensity), 2) interference with general activities of daily living (ADL), and 3) face-specific pain interference. The objective of this paper is to determine the patient-reported minimum clinically important difference (MCID) using the BPI-Facial.

METHODS The authors conducted a retrospective study of 234 patients with TN seen in a single neurosurgeon's office. Patients completed baseline and 1-month follow-up BPI-Facial questionnaires. The MCID was calculated using an anchor-based approach in which the defined anchor was the 7-point patient global impression of change (PGIC). Two statistical methods were employed: mean change score and optimal cutoff point.

RESULTS Using the mean change score method, the investigators calculated the MCID for the 3 domains of the BPIFacial: $44 \%$ and $30 \%$ improvement in pain intensity at its worst and average, respectively, $54 \%$ improvement in interference with general $A D L$, and $63 \%$ improvement in interference with facial $A D L$. Using the optimal cutoff point method, they also calculated the MCID for the 3 domains of the BPI-Facial: $57 \%$ and $28 \%$ improvement in pain intensity at its worst and average, respectively, $75 \%$ improvement in interference with general ADL, and $62 \%$ improvement in interference with facial ADL.

CONCLUSIONS The BPI-Facial is a multidimensional pain scale that measures 3 domains of pain. Although 2 statistical methods were used to calculate the MCID, the optimal cutoff point method was the superior one because it used data from the majority of subjects included in this study. A $57 \%$ improvement in pain intensity at its worst and a $28 \%$ improvement in pain intensity at its average were the MCIDs for patients with facial pain. A greater improvement was needed to achieve the MCID for interference with general and facial ADL. A 75\% improvement in interference with general ADL and a $62 \%$ improvement in interference with facial $A D L$ were needed to achieve an MCID. While pain intensity is easier to measure, pain's interference with ADL may be more important for patient outcomes when designing or evaluating interventions in the field of TN. The BPI-Facial is a useful instrument to measure changes in multidimensional aspects of pain in patients with $\mathrm{TN}$.

http://thejns.org/doi/abs/10.3171/2014.8.JNS132547

KEY WORDS trigeminal neuralgia; facial pain; Brief Pain Inventory; Brief Pain Inventory-Facial; minimum clinically important difference; functional neurosurgery

$\mathrm{N}$ EUROSURGEONS are often critically involved in the diagnosis, management, and surgical treatment of patients with facial pain. Neurosurgeons have decades of experience in the management of such patients, but the measurement of pain remains a challenge. Part of the challenge is that pain is a unique experience that no other person can feel or perceive on one's behalf. Even if a group of individuals receives the same stimuli or undergoes the same intervention, there is a large range in reported pain ratings. ${ }^{11,32}$ The subjective nature of pain makes it difficult to study in a quantifiable manner, and it requires the use of patients' verbal accounts and memo-

ABBREVIATIONS ADL = activities of daily living; $A U C=$ area under the ROC curve; $B P I=$ Brief Pain Inventory; MCID = minimum clinically important difference; PGIC = patient global impression of change; $\mathrm{PRO}=$ patient-reported outcome; $\mathrm{ROC}=$ receiver operating characteristic; $\mathrm{TN}=$ trigeminal neuralgia.

SUBMITTED November 18, 2013. ACCEPTED August 27, 2014.

INCLUDE WHEN CITING Published online October 31, 2014; DOI: 10.3171/2014.8.JNS132547.

DISCLOSURE Dr. Farrar reports being a consultant for Pfizer and being a board member for the American Pain Society. 
ries. ${ }^{3,12}$ Thus, it is important to use patient-reported outcomes (PROs) in the measurement of pain relief following treatment for facial pain disorders.

The majority of neurosurgical studies on trigeminal neuralgia (TN) pain have not used PROs and make no attempt to quantify pain. For example, many published studies that have evaluated pain intensity outcomes following neurosurgical intervention used either a 3- or 5-point scale to measure pain, and these scales relied on the physician's assessment of pain relief and not on the patient's reporting. ${ }^{1,27}$ In addition, a literature review of surgical studies on TN revealed that 221 of 222 studies had not measured pain preoperatively, and therefore a comparison between baseline and postoperative pain could not be made. ${ }^{34} \mathrm{De}-$ spite decades of neurosurgical management of TN, quantifiable benefits are difficult to obtain. Recognizing the lack of quantifiable outcome measures in the study of TN and facial pain disorders, the senior author (J.Y.K.L.) adapted the Brief Pain Inventory (BPI) to evaluate patients with facial pain. ${ }^{24}$ The original BPI is an instrument that has been thoroughly vetted as a reliable and valid instrument. ${ }^{6}$ It has been translated into over 75 languages and has been used successfully in hundreds of clinical trials. The senior author's appended version of the BPI was named the Brief Pain Inventory-Facial (BPI-Facial). In 2010, the senior author published a study describing the instrument and carefully analyzing and defining its psychometric properties. ${ }^{24}$ In that study, the BPI-Facial was only administered at the initial visit; change score before and after intervention were not examined. In this current study, administration of the BPI-Facial before and after intervention provides insight into pain outcomes in a standardized format.

The challenge when using PROs is interpreting the change in instrument score and determining what magnitude of change should be considered clinically meaningful. ${ }^{21}$ Changes in pain intensity or interference with daily activities may result in statistically significant changes that are not clinically relevant. The concept of the minimum clinically important difference (MCID) has been defined by several authors, such as Jaeschke and colleagues, who defined it as the "smallest difference in score in the domain of interest which patients perceive as beneficial and which would mandate, in the absence of troublesome side effects and excessive cost, a change in the patient's management." ${ }^{21}$ This study investigates the MCID of the BPI-Facial change score in a cohort of patients who were evaluated by the senior author for neurosurgical intervention.

\section{Methods \\ Patient Sample}

This is a single center, institutional review board-approved, retrospective review of 234 patients seen between January 2006 and December 2011. The analysis includes data from patients who were evaluated by a single surgeon for TN. Patients seen in the office were asked to complete a paper questionnaire that included the BPI-Facial. After review of history, physical examination, and imaging, the senior surgeon (J.Y.K.L.) categorized patients' facial pain according to the Burchiel classification system and Inter- national Headache Society. ${ }^{4,19}$ Only patients with a diagnosis of TN (Type 1 or 2) were included in this study.

\section{Outcome Measures \\ BPI-Facial}

The BPI-Facial (Appendix 1) is composed of 18 questions that cover 3 domains of pain: 1) 4 questions that address pain intensity using the Numerical Rating Scale (NRS), ${ }^{6}$ 2) 7 questions that address pain interference with general activities of daily living (ADL) (general interference items), and 3) 7 questions that address pain interference with face-specific daily activities (facial interference items). ${ }^{21}$ The BPI-Facial uses an 11-point Likert scale, ranging from 0 to 10 for all 18 items. ${ }^{14}$

\section{Pain Intensity}

Pain intensity was measured for the 4 items of the NRS using a Likert scale of 11 choices, ranging from 0 ("no pain") to 10 ("pain as bad as you can imagine"). The 4 items are as follows: 1) pain at its worst, 2) pain at its least, 3) pain at its average, and 4) pain right now.

Although pain intensity was calculated at its worst, least, average, and at present, we only present data for NRS-worst and NRS-average pain, as this provides the greatest face validity. Hence, pain intensity is presented as 2 variables: 1) worst intensity of pain and 2) average intensity of pain.

\section{General Interference Items}

Interference with general $\mathrm{ADL}^{6}$ was measured for 7 different conditions using a Likert scale of 11 choices, ranging from 0 ("does not interfere") to 10 ("completely interferes"). The 7 items are as follows: 5) general activity, 6) mood, 7) walking ability, 8) normal work (includes both work outside the home and housework), 9) relations with other people, 10) sleep, and 11) enjoyment of life.

Although interference in each aforementioned activity was calculated, a composite general interference score was determined by averaging the 7 components of the scale.

\section{Facial Interference Items}

Interference with face-specific activities was measured for 7 different conditions using a Likert scale of 11 choices, ranging from 0 ("does not interfere") to 10 ("completely interferes"). ${ }^{24}$ The 7 items are as follows: 12) eating a meal, 13) touching your face (including grooming), 14) brushing or flossing your teeth, 15) smiling or laughing, 16) talking, 17) opening your mouth widely, and 18) eating hard foods like apples.

Although interference for each activity was calculated, a composite facial interference score was determined by averaging the 7 components of the scale.

\section{Patient Global Impression of Change}

In addition to completing the BPI-Facial at the time of their follow-up visit, patients completed the Patient Global Impression of Change (PGIC; Appendix 2). Follow-up visits were typically 30 days after the patient's procedure. During that visit, patients were not shown their initial BPIFacial questionnaires; therefore, they did not know the specific score they had chosen before treatment. However, 
since the follow-up period was short, patients were more likely to recall their preoperative pain.

The PGIC is a 7-point Likert scale of overall change in which patients are asked to choose 1 of 7 descriptors that best describes how their symptoms have improved or worsened..$^{14}$ The 7 categorical options are as follows: 1) very much improved, 2) much improved, 3) minimally improved, 4) no change, 5) minimally worse, 6) much worse, and 7) very much worse.

\section{Data Analysis}

There are many ways to calculate the minimal clinically important difference (MCID). One method is the anchor-based approach, where an external criterion, also known as the anchor, is used to compare the change observed in a PRO tool. ${ }^{7}$ In this study, the anchor was the PGIC, and the PRO tool was the BPI-Facial. Two statistical methods were used to compute the MCID using the anchor-based approach: mean change score and optimal cutoff point. ${ }^{33}$ Missing data were not imputed and all calculations were restricted to completed data elements. All statistical analyses were performed using STATA version 10 for Windows.

\section{Mean Change Score: Raw and Percentage Change}

For each patient, the raw and percentage change score was calculated for the 3 domains of the BPI-Facial: pain intensity, composite general interference, and composite facial interference. To calculate the raw change score, each patient's follow-up score was subtracted from his/ her baseline score. Hence, positive change scores reflect a decrease in pain intensity and a decrease in pain interference. The percentage change was calculated by dividing the raw change score by the baseline score.

\section{Optimal Cutoff Point}

The MCID was calculated using the optimal cutoff point method by plotting receiver operating characteristic (ROC) curves. ROC curves have been used as a tool to measure the classification performance of diagnostic or screening tests, namely, the ability to distinguish diseased from healthy individuals (http://knowledge.sagepub.com/ view/epidemiology/n394.xml). ${ }^{30}$ The diagnostic accuracy of the tool is determined by the area under the ROC curve (AUC). ${ }^{16,18,30}$ For the purposes of this study, the PGIC was used as the diagnostic test.

Three different models were created based upon the PGIC categories. The most stringent model only included patients who chose the descriptor "very much improved." The intermediate stringency model included patients who chose the descriptors "very much improved" or "much improved." The least stringent model included patients who chose the descriptors "very much improved," "much improved," or "minimally improved." ROC curves for each stringency model were created for the 3 domains of the BPI-Facial (pain intensity, composite general interference, and composite facial interference).

The intermediate stringency model has been commonly used as the definition of the MCID, when using the 7-point PGIC..$^{33}$ To calculate the optimal cutoff point
(MCID) for the intermediate stringency model, subjects were grouped into a dichotomous outcome: "better" and "not better." The "better" group was defined as the patients who chose either 1) "very much improved" or 2) "much improved" on the PGIC. The remaining patients were defined as "not better." ROC curves were then created by respectively plotting sensitivity and 1-specificity on the $y$ - and $x$-axis on a 2D square plot for a series of cutoff points. Sensitivity was defined as the number of patients who were correctly identified as "better," and specificity was defined as the number of patients correctly identified as "not better." 12 The Youden index (J) was used to determine the optimal cutoff point. $\mathrm{J}$ is the point on the ROC curve that maximizes the test's differentiating ability, while equally weighing sensitivity and specificity. ${ }^{30}$ The index is the "maximum vertical distance between the ROC curve and the diagonal or chance line." ${ }^{9,30}$

The AUC was also calculated. The AUC represented the probability that change scores correctly discriminated patients who were "better" from those who were "not better." 10,16 According to Hosmer and Lemeshow, an AUC of 0.7-0.79 was considered to be acceptable discrimination, $0.8-0.9$ to be excellent discrimination, and greater than 0.9 to be outstanding discrimination. ${ }^{20}$

\section{Results}

\section{Patient Characteristics}

Of the 234 subjects included in this analysis, 207 (88\%) subjects completed majority of the 18-item BPI-Facial questionnaire at their baseline and follow-up visit, as well as the PGIC at the follow-up visit. The mean age of the subjects in the study was 62.1 years, and $62 \%$ of the subjects were female. The mean follow-up period between baseline and follow-up visit was 3.7 months, and the mean time between surgical procedure and follow-up visit was 1.4 months. Characteristics of the patients are summarized in Table 1.

The majority of patients were diagnosed with Burchiel Type $1 \mathrm{TN}$ (79\%); the remaining patients were diagnosed with Burchiel Type 2 TN (Table 2). In addition, the V2 and V3 distributions were the most commonly affected distributions of pain, and just more than half of patients had right-sided pain (56\%).

Two hundred thirty patients underwent at least one of the following neurosurgical interventions: microvascular decompression (46\%), Gamma Knife radiosurgery (47\%), and percutaneous glycerol rhizotomy (5.1\%) (Table 2). Four patients who did not undergo a procedure attended follow-up visits at which they completed the BPI-Facial questionnaire. Those 4 patients were included in this analysis because their pain should theoretically not have changed and thus their scores should not have changed.

\section{Patient Distribution of the PGIC}

Of the 207 subjects, 77 characterized themselves as either "very much improved" or "much improved" (Fig. 1). Fourteen percent of all subjects had characterized themselves as having "no change," being "minimally worse," or being "much worse." No patient rated himself or herself as "very much worse." 
TABLE 1. Patient characteristics

\begin{tabular}{lc}
\hline \multicolumn{1}{c}{ Parameter } & No. of Patients/Value (\%) \\
\hline Total no. of patients & 234 \\
\hline No. of females & $144(62)$ \\
\hline Mean age \pm SD (yrs) & $62.1 \pm 14.3$ \\
\hline No. of op-treated patients & $229(98)$ \\
\hline V1 distribution & $62(26)$ \\
\hline V2 distribution & $174(74)$ \\
\hline V3 distribution & $157(67)$ \\
\hline No. w/ lt-sided pain (\%) & $103(44)$ \\
\hline No. w/ bilat pain & 0 \\
\hline
\end{tabular}

\section{Calculating the MCID}

\section{Mean Change Score: Raw and Percentage}

The raw and percentage change scores were calculated for the 3 domains of the BPI-Facial (pain intensity, composite general interference, and composite facial interference) (Tables 3 and 4). Box plot analysis revealed that the average intensity of pain had the smallest distribution of change scores on the BPI-Facial, while the worst intensity of pain had the largest distribution of change score (Fig. 2).

The raw and percentage changes for the worst and average pain intensity were calculated for each of the 7 categories of the PGIC (Table 3). This allows the readers to choose the appropriate MCID for their own particular study or area of interest-since researchers with an interest in a medication with minimal side effects may choose a less stringent criterion for MCID, whereas researchers with an interest in a new invasive surgical procedure may choose a more stringent criterion for MCID. For the purposes of this study, the mean change score method of MCID calculation was determined by patients who reported "much improved" outcomes on the PGIC. The MCID was a $44 \%$ reduction in worst pain intensity and a $30 \%$ reduction in average pain intensity (Table 3 ).

Since pain was not only measured on an intensity scale but also with respect to how it interfered with ADL, the MCID for the composite general interference score and composite facial interference score of the BPI-Facial questionnaire was also calculated. Table 4 provides the average raw and percentage change score for each category of the PGIC. Patients who reported "much improved" outcomes on the PGIC determined the MCID for this method. The MCID was a $54 \%$ reduction in general interference and a $63 \%$ reduction in facial interference. In comparison with pain intensity, a greater percentage improvement was needed for both general and facial interference items for patients to rate their change as clinically significant.

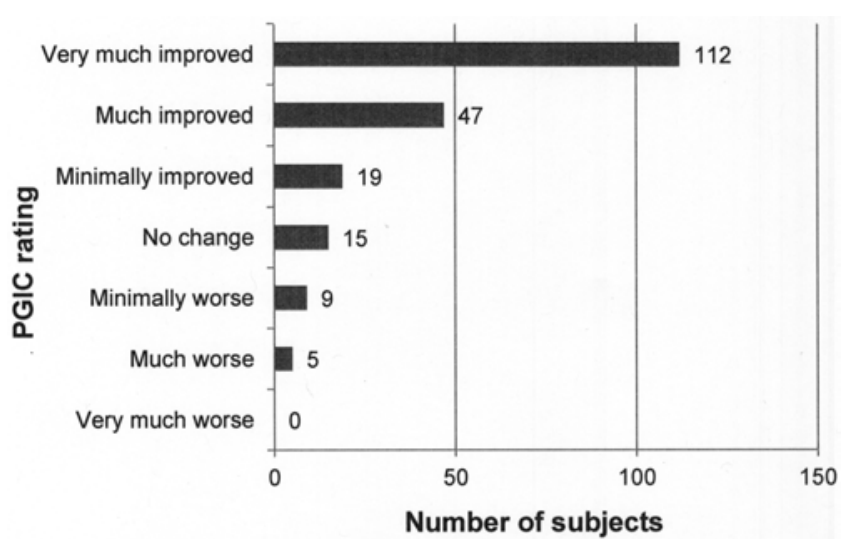

FIG. 1. Bar graph displaying the patient distribution for each category of the PGIC, or the Patient Global Impression of Change. The majority of patients $(77 \%)$ characterize themselves as either "very much improved" or "much improved."

\section{Optimal Cutoff Point}

We present the selected cutoff points (MCID) for the 3 domains of the BPI-Facial (pain intensity, composite general interference, and composite facial interference) in raw and percentage format in Tables 5 and 6 . We present the results using the intermediate stringency model (patients who were "very much improved" and "much improved"). The MCID was a $57 \%$ reduction in worst pain intensity and a $28 \%$ reduction in average pain intensity. This result is similar to the mean change method of calculating the MCID (refer to Table 7).

The optimal cutoff point method was also used to calculate the MCID for the composite general interference score and the composite facial interference score (Fig. 3). The same 3 models of varying stringency were used to generate ROC curves for the composite general and facial interference scores (Table 6). We present the results using the intermediate stringency model. The MCID was a $75 \%$ reduction in composite general interference and a $62 \%$ reduction in composite facial interference. Similar to the mean change score method, the optimal cutoff point method yielded MCID values that were higher for the interference items than for the pain intensity items (Table 7).

\section{Discussion}

This study provides quantitative data using a reliable and validated outcome tool in the measurement of pain in patients with TN before and after intervention. Patients self-rated their own improvement in this study, and the change scores are based on the patient's perception of clinical relevance-the MCID. This is the first paper in

TABLE 2. Diagnosis stratified by treatment

\begin{tabular}{lccccc}
\hline & \multicolumn{4}{c}{ Procedure } & No. of \\
\cline { 2 - 6 } \multicolumn{1}{c}{ Diagnosis } & Gamma Knife & Microvascular Decompression & Percutaneous Glycerol Rhizotomy & Procedures & Total \\
\hline Burchiel Type 1 TN & 88 & 85 & 10 & 3 & 186 \\
\hline Burchiel Type 2 TN & 23 & 22 & 2 & 1 & 48 \\
\hline Total & 111 & 107 & 12 & 4 & 234 \\
\hline
\end{tabular}


TABLE 3. Raw and percentage change of score for the pain intensity domain of the BPI-Facial: worst and average pain intensity*

\begin{tabular}{|c|c|c|c|c|}
\hline \multirow[b]{2}{*}{ PGIC } & \multicolumn{2}{|c|}{ NRS: Raw Change } & \multicolumn{2}{|c|}{ NRS: Percentage Change } \\
\hline & Worst & Average & Worst & Average \\
\hline Very much improved & $7.0 \pm 0.3$ & $2.7 \pm 0.2$ & $87.1 \pm 2.4$ & $44.5 \pm 1.2$ \\
\hline Much improved & $4.1 \pm 0.6$ & $1.8 \pm 0.2$ & $43.7 \pm 8.4$ & $29.8 \pm 2.7$ \\
\hline Minimally improved & $1.9 \pm 1.0$ & $1.1 \pm 0.3$ & $-31.0 \pm 62.5 \dagger$ & $6.9 \pm 12.1$ \\
\hline No change & $2.0 \pm 1.0$ & $0.5 \pm 0.6$ & $18.6 \pm 15.1$ & $7.6 \pm 10.9$ \\
\hline Minimally worse & $0.3 \pm 0.6$ & $0.6 \pm 0.4$ & $0.2 \pm 8.6$ & $6.9 \pm 4.9$ \\
\hline Much worse & $-1.0 \pm 2.1$ & $-0.3 \pm 0.6$ & $-47.8 \pm 50.0$ & $-11.0 \pm 10.6$ \\
\hline Very much worse & - & - & - & - \\
\hline \multicolumn{5}{|c|}{$\begin{array}{l}-=\text { not applicable. } \\
\text { * Values are presented as the mean } \pm \text { SD. Boldface type represents the "suggested" threshold for the MCID. } \\
\dagger \text { The percentage change in this example is heavily influenced by } 4 \text { individuals. One individual rated pain at the worst as } 1 \text { but at next follow-up } \\
\text { described their pain as } 10 \text {. The percentage change for this individual is }[(1-10) \times 100) / 1] \text {, which is equal to a }-900 \% \text { change. Hence, the } \\
\text { values are significantly skewed by this despite the raw change being on average only } 6.9 \text {. }\end{array}$} \\
\hline
\end{tabular}

the neurosurgical literature that defines the MCID using a well-validated tool such as the BPI-Facial. It should help to set a standard by which future studies assess facial pain.

Many working groups have suggested that outcome studies in pain should use multidimensional outcome tools. For example, the multiinstitutional Initiative on Methods, Measurement, and Pain Assessment in Clinical Trials (IMMPACT) defined 6 core domains to be considered in treatment trials of chronic pain: 1) pain intensity, 2) physical functioning, 3) emotional functioning, 4) participant ratings of improvement and satisfaction with treatment, 5) symptoms and adverse events, and 6) participant adherence to treatment regimen. ${ }^{31}$ This study investigated 3 domains of pain: pain intensity, interference with general ADL, and interference with face-specific ADL. The percentage threshold change required for patients to rate themselves as improved was higher for the interference items than for the 2 intensity items alone (Table 7). For example, a $30 \%$ improvement in pain intensity at its average was enough for patients to rate themselves as "much improved," but a $30 \%$ improvement in pain interference with either general or facial ADL was insufficient for patients to rate themselves as "much improved." Thus, although it is the severity of pain that leaves a lasting impression on practitioners who see $\mathrm{TN}$ patients in the office, it is the effect of that pain on an individuals' ADL that they want cured. Hence, the MCID was $57 \%$ for pain intensity at its worst and $28 \%$ for pain intensity at its average, but the MCIDs for the composite general and facial interference scores were $75 \%$ and $62 \%$, respectively. This supports the concept that pain is multidimensional and cannot be simply measured on intensity alone.

There is one article in the available literature that presents data on the MCID in TN patients. ${ }^{26}$ Reddy and colleagues presented data on 60 patients who underwent microvascular decompression. These authors used the visual analog scale and the Barrow Neurological Institute Pain Scale and calculated the MCID using the anchorbased approach. ${ }^{5}$ Unfortunately, the visual analog scale is a 1-question measure of pain intensity and does not test additional dimensions of pain. In addition, the Barrow scale has not been validated for use as an outcome tool, although it is widely used. Perhaps because of a small sample size, Reddy et al. found widely varying results for the MCID and, in an effort to reconcile the large variance in the results, the authors simply averaged the high and low scores. This method is circumspect, considering that each method employs a different calculation technique and the methods are not statistically equivalent in weight or importance. Nevertheless, the authors do provide insight into some of the difficulties in measuring pain before and after intervention.

TABLE 4. Raw and percentage change of scores for two of the domains of the BPI-Facial questionnaire: composite general interference and composite facial interference*

\begin{tabular}{lccccc}
\hline \multirow{2}{*}{ PGIC } & \multicolumn{2}{c}{ General Interference } & & \multicolumn{2}{c}{ Facial Interference } \\
\cline { 2 - 3 } \cline { 5 - 6 } & Raw Change & Percentage Change & & Raw Change & Percentage Change \\
\hline Very much improved & $5.5 \pm 0.3$ & $92.3 \pm 2.1$ & & $6.9 \pm 0.3$ & $96.3 \pm 1.1$ \\
\hline Much improved & $3.4 \pm \mathbf{0 . 6}$ & $\mathbf{5 3 . 5 \pm 1 0 . 6}$ & & $\mathbf{4 . 2} \pm \mathbf{0 . 6}$ & $\mathbf{6 3 . 1} \pm \mathbf{6 . 4}$ \\
\hline Minimally improved & $2.9 \pm 0.8$ & $35.0 \pm 12.1$ & & $2.5 \pm 1.2$ & $20.4 \pm 23.6$ \\
\hline No change & $2.3 \pm 0.7$ & $41.6 \pm 12.4$ & & $1.8 \pm 1.1$ & $24.9 \pm 15.2$ \\
\hline Minimally worse & $0.5 \pm 1.1$ & $0.68 \pm 17.9$ & & $0.8 \pm 1.0$ & $5.7 \pm 11.6$ \\
\hline Much worse & $-1.6 \pm 1.1$ & $-20.1 \pm 23.0$ & & $-4.3 \pm 0.9$ & $-170.8 \pm 120.8$ \\
\hline Very much worse & - & - & & - & - \\
\hline
\end{tabular}

* Values are presented as the mean \pm SD. Boldface type represents the "suggested" threshold for the MCID. 

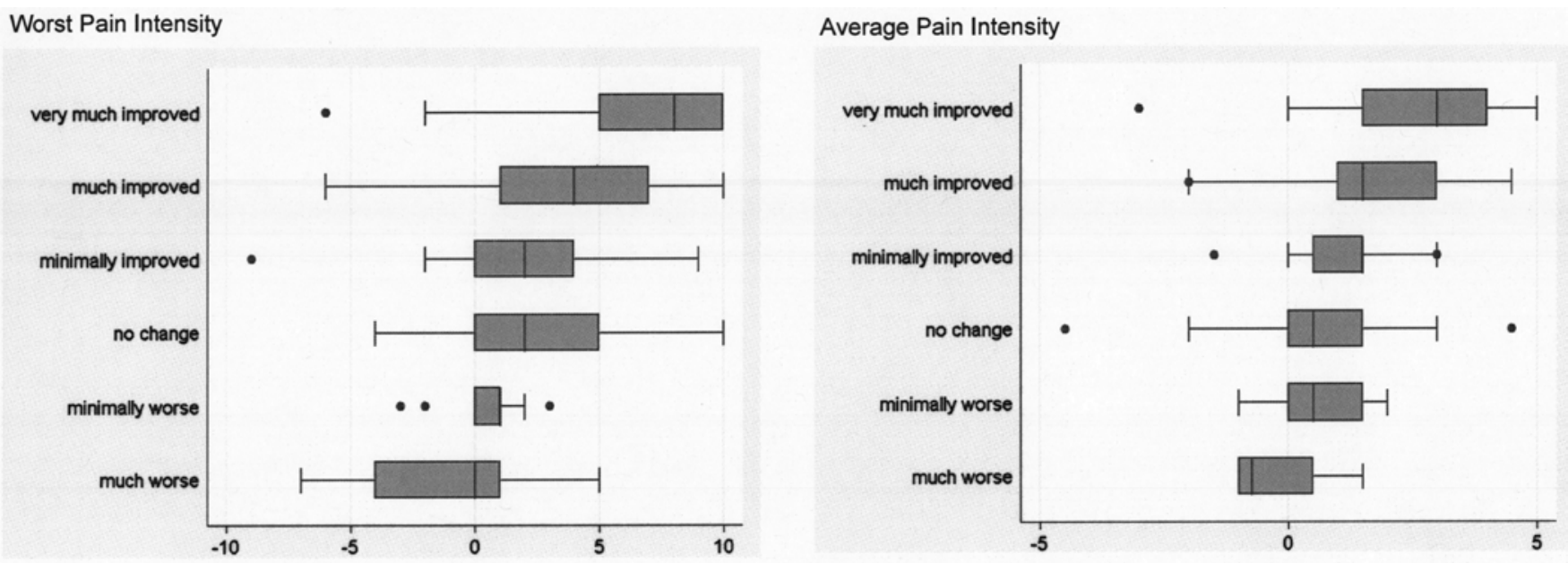

Composite General Interference
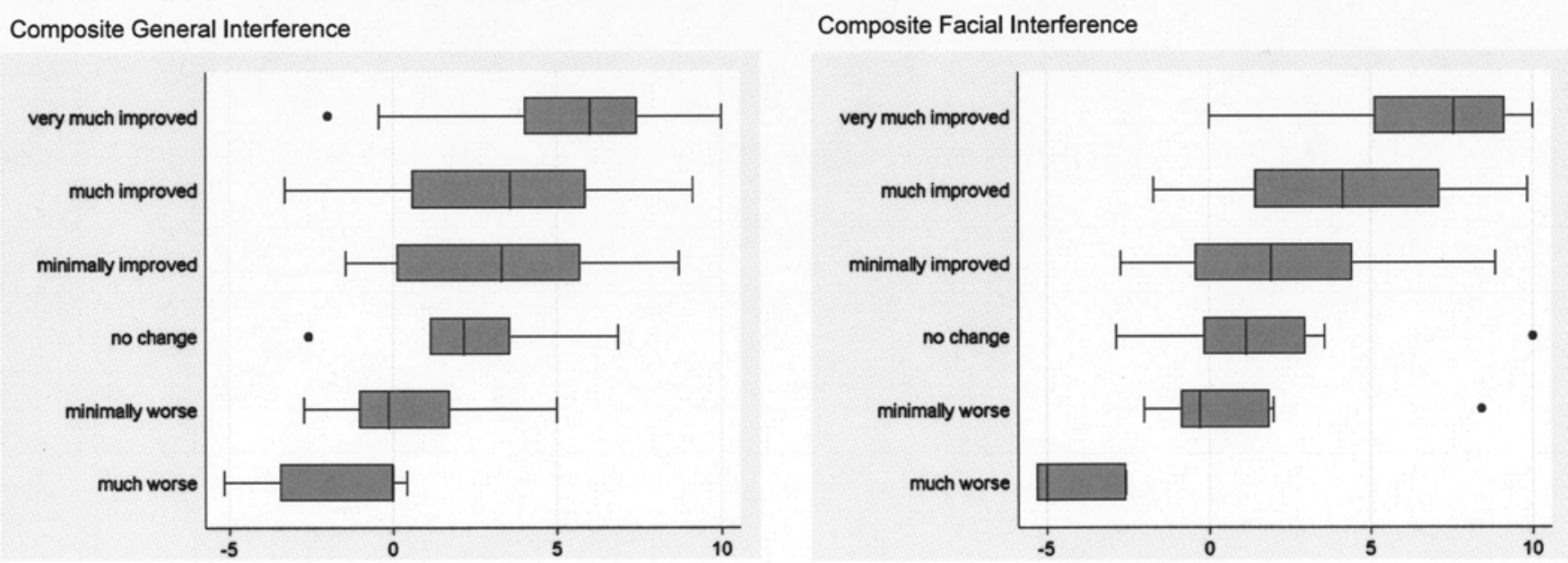

FIG. 2. Box plots for the raw change score for the 3 domains of the BPI-Facial. Each domain is stratified by the 7 PGIC categories. Average pain intensity has the smallest change in score in almost every category of the PGIC. The "much improved" group has a wide distribution of scores for the 3 domains. Dots represent extremes and hatches represents quartiles.

TABLE 5. Raw and percentage change optimal cutoff points determined by the pain intensity domain of the BPI-Facial: worst and average pain intensity*

\begin{tabular}{|c|c|c|c|c|c|c|c|}
\hline Outcome Measure & $\begin{array}{c}\text { Raw/Percentage } \\
\text { Change }\end{array}$ & Model & Cutoff Point & Sensitivity (\%) & Specificity (\%) & AUC & $\begin{array}{l}\text { Percentage } \\
\text { Correct (\%) }\end{array}$ \\
\hline \multirow{6}{*}{ Worst pain intensity } & \multirow{3}{*}{ Raw } & Very much improved & 7 & 65.4 & 83.3 & 0.81 & 73.5 \\
\hline & & Much \& very much improved & 6 & 65.5 & 90.7 & 0.83 & 71.4 \\
\hline & & Minimally, much, \& very much improved & 4 & 71.3 & 82.1 & 0.82 & 73.0 \\
\hline & \multirow{3}{*}{ Percentage } & Very much improved & 70 & 83.3 & 78.6 & 0.87 & 81.1 \\
\hline & & Much \& very much improved & 57 & 75.9 & 88.4 & 0.87 & 78.9 \\
\hline & & Minimally, much, \& very much improved & 40 & 79.0 & 82.1 & 0.85 & 79.4 \\
\hline \multirow{6}{*}{$\begin{array}{l}\text { Average pain inten- } \\
\text { sity }\end{array}$} & \multirow{3}{*}{ Raw } & Very much improved & 2.5 & 66.3 & 75.3 & 0.75 & 70.4 \\
\hline & & Much \& very much improved & 2 & 65.7 & 81.0 & 0.78 & 69.3 \\
\hline & & Minimally, much, \& very much improved & 1.5 & 73.0 & 70.4 & 0.79 & 72.6 \\
\hline & \multirow{3}{*}{ Percentage } & Very much improved & 40 & 82.6 & 83.1 & 0.87 & 82.8 \\
\hline & & Much \& very much improved & 27.8 & 83.6 & 82.9 & 0.88 & 83.4 \\
\hline & & Minimally, much, \& very much improved & 27.8 & 77.6 & 88.5 & 0.86 & 79.3 \\
\hline
\end{tabular}

* Cutoff points were calculated using the Youden index. Boldface type represents the "suggested" threshold for the MCID. 
TABLE 6. Raw and percentage change optimal cutoff points determined by two domains of the BPI-Facial: composite general interference and composite facial interference*

\begin{tabular}{|c|c|c|c|c|c|c|c|}
\hline Outcome Measure & $\begin{array}{l}\text { Raw/Percentage } \\
\text { Change }\end{array}$ & Model & Cutoff Point & Sensitivity (\%) & Specificity (\%) & AUC & $\begin{array}{l}\text { Percentage } \\
\text { Correct (\%) }\end{array}$ \\
\hline \multirow{6}{*}{$\begin{array}{l}\text { Composite general } \\
\text { interference }\end{array}$} & \multirow{3}{*}{ Raw } & Very much improved & 4 & 75.9 & 70.6 & 0.75 & 73.6 \\
\hline & & Much \& very much improved & 3.7 & 68.3 & 80 & 0.77 & 71.0 \\
\hline & & Minimally, much, \& very much improved & 2.7 & 75.2 & 77.3 & 0.81 & 75.5 \\
\hline & \multirow{3}{*}{ Percentage } & Very much improved & 94.5 & 78.6 & 84.6 & 0.85 & 81.3 \\
\hline & & Much \& very much improved & 75 & 81.9 & 85.3 & 0.85 & 82.7 \\
\hline & & Minimally, much, \& very much improved & 70 & 78.3 & 90.5 & 0.84 & 80.0 \\
\hline \multirow{6}{*}{$\begin{array}{l}\text { Composite facial in- } \\
\text { terference }\end{array}$} & \multirow{3}{*}{ Raw } & Very much improved & 4.7 & 79.3 & 73.9 & 0.81 & 77.0 \\
\hline & & Much \& very much improved & 2.28 & 80.0 & 71.9 & 0.84 & 78.3 \\
\hline & & Minimally, much, \& very much improved & 3.7 & 73.1 & 90.9 & 0.85 & 75.7 \\
\hline & \multirow{3}{*}{ Percentage } & Very much improved & 85.5 & 92.9 & 74.6 & 0.89 & 85.0 \\
\hline & & Much \& very much improved & 61.5 & 87.2 & 83.3 & 0.90 & 86.4 \\
\hline & & Minimally, much, \& very much improved & 45.8 & 88.9 & 85.7 & 0.88 & 88.4 \\
\hline
\end{tabular}

* Cutoff points were calculated using the Youden index. Boldface type represents the "suggested" threshold for the MCID.

\section{Methodology}

Of the 2 methods used in this paper for calculating the MCID, the optimal cutoff point method with ROC curve analysis was the superior method because it used all available data and maximized classification; therefore, this method was used to determine the threshold MCID values for this study. The mean change score method of calculating the MCID was simple to perform, but it ignored a significant amount of data. For example, if we had defined the "much improved" group as the MCID, only 47 patients would have been used to calculate the mean change score. The mean change score method would have discarded the change scores for all the other patients who had rated themselves in another category of the PGIC. In contrast, ROC curve analysis was performed utilizing the change scores for every patient to correctly classify patients who were "better" and those who were "not better." Hence, the preferred method for calculation of the MCID was the optimal cutoff point method. Despite this, we recognize that sensitivity and specificity in this study ranged from $65 \%$ to $93 \%$ and that it was not uniformly greater than $90 \%$. However, the AUC ranged from 0.85 to 0.9 for the percentage change scores for the 3 components of the BPI-Facial questionnaire. The AUC values indicated the BPI-Facial questionnaire's ability to discriminate patients who were "better" from those who were not. According to Hosmer-Lemeshow criteria, our values are indicative of excellent discrimination between "better" and "not better" patients. ${ }^{20}$

The results that we present appear to have internal consistency. Raw change scores are presented alongside percentage change scores, since studies have shown that a 1-point decrease in pain from 3 to $2(33 \%)$ is more significant than a 1-point decrease in pain from 10 to $9(10 \%) .^{14}$ One caveat is that we have presented the average of 7 general interference items and the average of 7 facial interference items. Although the raw averaged numbers can be compared, we are less confident about the validity of presenting the percentage scores of the averaged 7 items because their statistical equivalence cannot be assured.
Additional research is needed to determine the underlying importance of each specific question of the BPI-Facial questionnaire and its correlation to TN. ${ }^{13}$ Nevertheless, we are encouraged because the AUC for the percentage values were larger than the the raw value AUC (Tables 5 and 6). Thus, we believe that perhaps for this patient population, utilizing the percentages of averaged values is acceptable.

We omitted 2 measures of pain intensity: "pain at its least" and "pain right now." "Pain at its least" was excluded from the analysis because the values were similar to "pain at its average," and it did not contribute any significant data to the study. "Pain right now" was excluded from the analysis because scores can vary greatly and may be confounded by many factors, including what the patient was doing before they filled out the survey. ${ }^{13}$

\section{Future Directions}

This study has practical value in an era of comparative effectiveness analysis. Future interventions in patients with TN and facial pain may need to specify criterion for success after medical or surgical intervention. For example, a prospective study may have to calculate a power analysis and sample size with an a priori plan to detect a $30 \%$ change in average pain intensity and a $70 \%$ change in composite general interference score and composite facial interference score. In this way, a new procedure or new treatment for patients with refractory facial pain can be validated and hopefully approved. ${ }^{17,23}$ Fortunately, patients

TABLE 7. Summary of percentage MCID using "much improved" as anchor criterion

\begin{tabular}{lcc}
\hline \multicolumn{1}{c}{ BPI-Facial Domain } & $\begin{array}{c}\text { Mean Change } \\
\text { (percentage) }\end{array}$ & $\begin{array}{c}\text { Optimal Cutoff } \\
\text { (percentage) }\end{array}$ \\
\hline Worst pain intensity & 44 & 57 \\
\hline Average pain intensity & 30 & 27.8 \\
\hline Composite general interference & 54 & 75 \\
\hline Composite facial interference & 63 & 61.5 \\
\hline
\end{tabular}


Worst Pain Intensity

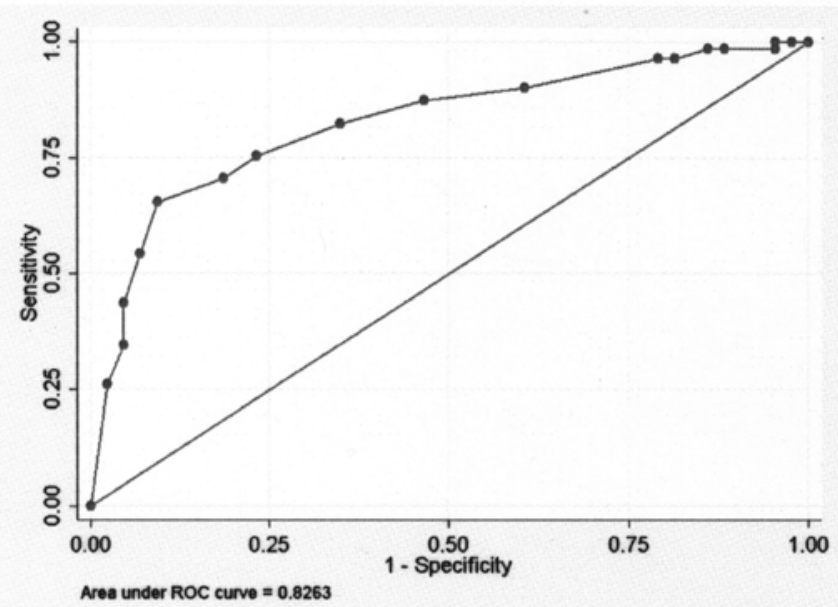

Composite General Interference

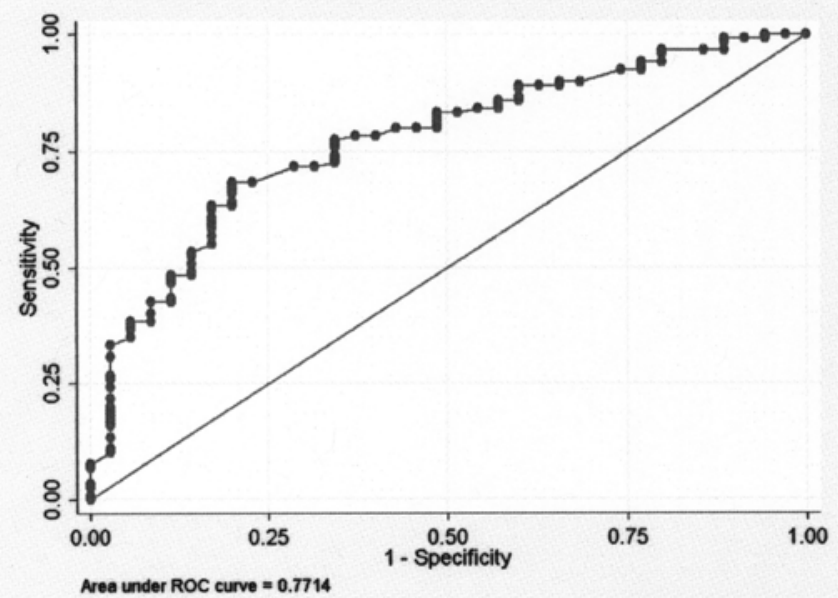

Average Pain Intensity

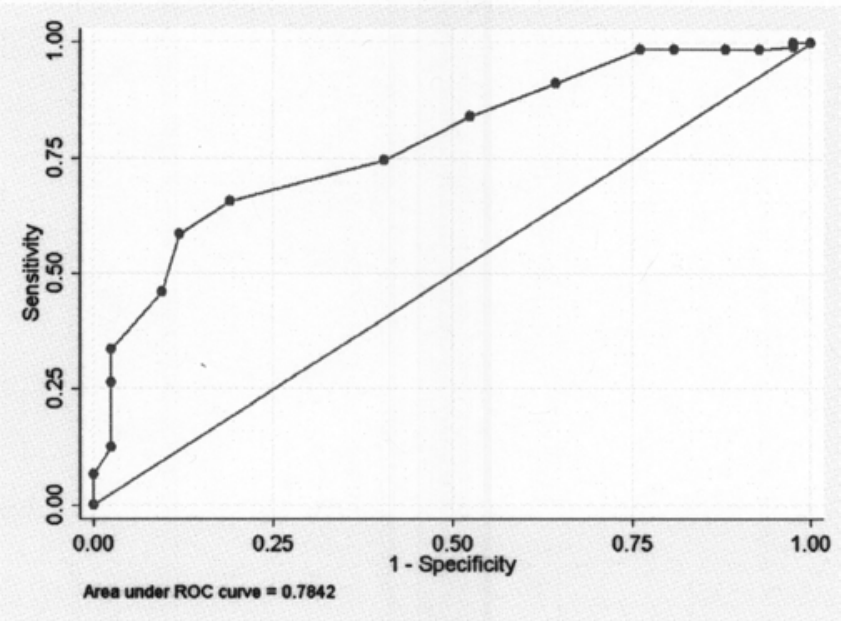

Composite Facial Interference

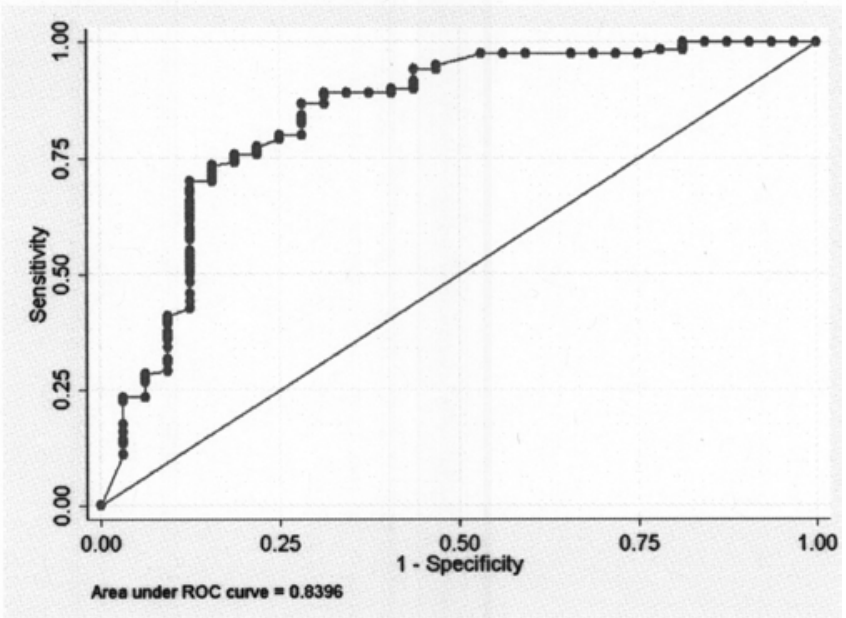

FIG. 3. ROC curves for the 3 domains of the BPI-Facial. The AUC for the 4 respective ROC curves are $0.83,0.78,0.77$, and 0.83. The AUCs represent the probability of correctly discriminating patients who are "better" from those who are "not better." The scores fall within acceptable to excellent ranges.

with TN have had great success with microvascular decompression, Gamma Knife treatment, and glycerol rhizotomy; however, patients with atypical facial pain continue to suffer from a lack of validated treatment options. ${ }^{5}$

\section{Limitations}

One of the difficulties of studying subjective data, like pain, is that statistically significant differences between numeric pain scores may yield scientifically valid results, but those results may only provide negligible benefit for patients. Recognizing this problem, many investigators have described methods to calculate the MCID. The anchor-based method has a common flaw - that is, the reliance on a single question or anchor-which in our case is the PGIC. The use of a single anchor to validate study results has been challenged. ${ }^{25}$ For example, the PGIC may be confounded by variables such as complications, comorbidities, and cognitive status. However, the PGIC has been well validated, and many investigators have used this single scale as an anchor or measure of comparison for other outcome tools. ${ }^{2,22,29,33}$ The PGIC also takes other factors into account that patients consider when rating their overall improvement, such as the following: sleep disturbance, cognitive dysfunction, depressive symptoms, and physical functioning. ${ }^{15}$ Despite its limitations, the PGIC, we believe, is a valid anchor for calculation of the MCID.

Recall bias is a significant concern in a study like this. The present study was intentionally designed to study time points that were in close proximity to minimize recall bias. Authors of many clinical studies on TN pain have been interested in the maximum follow-up time so that patients' experiences can be studied longitudinally. However, subjects have difficulty recalling their prior state of health; they tend to forget their pain intensity and interference over time. ${ }^{28}$ In addition, the scores they select on follow-up PRO measures are often derived from their current state of health, since they have difficulty recalling their baseline scores. ${ }^{28}$ Thus, patients may inaccurately report 
their perceived progress. Crosby et al. had found that over an extended period of time, global rating scores might be flawed because scores might inaccurately portray the patient's true clinical change. ${ }^{8}$ We believe that by minimizing follow-up time, subjects would be able to provide more accurate estimates of change in pain intensity and interference. Since the goal of the study was to define properties of the BPI-Facial instrument, longitudinal changes over time and the treatment received are less important than the characteristics of the specific instrument under study. Future studies will address long-term change in the BPIFacial results.

Lastly, another limitation of the study is its generalizability. Our prioritized patients with TN undergo surgery, since these patients have been referred for neurosurgical consult. Only 4 patients treated with medical management were included in this study. Future research could include a larger cohort of medically managed TN patients, which will improve generalizability of the BPI-Facial for this population.

\section{Conclusions}

In conclusion, we hope that this paper will set a standard for pain outcome research in neurosurgery for patients with TN. It is important to use PRO measures, like the BPI-Facial questionnaire, to evaluate pain intensity and how pain interferes with ADL. The BPI-Facial instrument is a multidimensional tool that appears to accomplish these tasks. We calculated the MCID for the 3 domains of the BPI-Facial: $57 \%$ and $28 \%$ improvement in pain intensity at its worst and average, respectively, $75 \%$ improvement in interference with general ADL, and 62\% improvement in interference with facial ADL. The BPIFacial is sensitive to change and measures 3 domains of facial pain. We encourage practitioners to employ the BPIFacial in their outcomes studies of these challenging but often grateful patients.

\section{Appendix 1}

\section{The Brief Pain Inventory-Facial}

Circle the ONE number that describes how, during the past week, pain has interfered with your:

1. General activity

$\begin{array}{llllllllllr}0 & 1 & 2 & 3 & 4 & 5 & 6 & 7 & 8 & 9 & 10 \\ \text { Does not } \\ \text { interfere }\end{array}$

2. Mood

$\begin{array}{ccccccccccc}0 & 1 & 2 & 3 & 4 & 5 & 6 & 7 & 8 & 9 & 10 \\ \begin{array}{l}\text { Does not } \\ \text { interfere }\end{array} & & & & & & & \begin{array}{l}\text { Completely } \\ \text { interferes }\end{array}\end{array}$

3. Walking ability

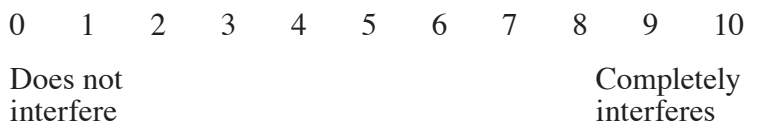

4. Normal work (includes both work outside the home and housework)

$\begin{array}{lllllllllrr}0 & 1 & 2 & 3 & 4 & 5 & 6 & 7 & 8 & 9 & 10 \\ \text { Does not } \\ \text { interfere }\end{array}$

5. Relations with other people

$\begin{array}{llllllllllr}0 & 1 & 2 & 3 & 4 & 5 & 6 & 7 & 8 & 9 & 10 \\ \text { Does not } \\ \text { interfere }\end{array}$

6. Sleep

$\begin{array}{lllllllllrr}0 & 1 & 2 & 3 & 4 & 5 & 6 & 7 & 8 & 9 & 10 \\ \begin{array}{l}\text { Does not } \\ \text { interfere }\end{array} & & & & & & & \begin{array}{l}\text { Completely } \\ \text { interferes }\end{array}\end{array}$

7. Enjoyment of life

$\begin{array}{lllllllllrr}0 & 1 & 2 & 3 & 4 & 5 & 6 & 7 & 8 & 9 & 10 \\ \begin{array}{l}\text { Does not } \\ \text { interfere }\end{array} & & & & & & & \begin{array}{l}\text { Completely } \\ \text { interferes }\end{array}\end{array}$

8. Eating a meal

$\begin{array}{llllllllllr}0 & 1 & 2 & 3 & 4 & 5 & 6 & 7 & 8 & 9 & 10 \\ \text { Does not } \\ \text { interfere }\end{array}$

9. Touching your face (including grooming)

$\begin{array}{lllllllllrr}0 & 1 & 2 & 3 & 4 & 5 & 6 & 7 & 8 & 9 & 10 \\ \begin{array}{l}\text { Does not } \\ \text { interfere }\end{array} & & & & & & & \begin{array}{l}\text { Completely } \\ \text { interferes }\end{array}\end{array}$

10. Brushing or flossing your teeth

$\begin{array}{lllllllllrr}0 & 1 & 2 & 3 & 4 & 5 & 6 & 7 & 8 & 9 & 10 \\ \text { Does not } \\ \text { interfere }\end{array}$

11. Smiling or laughing

$\begin{array}{llllllllllrr}0 & 1 & 2 & 3 & 4 & 5 & 6 & 7 & 8 & 9 & 10 \\ \begin{array}{l}\text { Does not } \\ \text { interfere }\end{array} & & & & & & & \begin{array}{l}\text { Completely } \\ \text { interferes }\end{array}\end{array}$

12. Talking

$\begin{array}{llllllllllrr}0 & 1 & 2 & 3 & 4 & 5 & 6 & 7 & 8 & 9 & 10 \\ \text { Does not } \\ \text { interfere }\end{array}$

13. Opening your mouth widely

$\begin{array}{lllllllllrr}0 & 1 & 2 & 3 & 4 & 5 & 6 & 7 & 8 & 9 & 10 \\ \text { Does not } \\ \text { interfere }\end{array}$

14. Eating hard foods like apples

$\begin{array}{lllllllllrr}0 & 1 & 2 & 3 & 4 & 5 & 6 & 7 & 8 & 9 & 10 \\ \text { Does not } \\ \text { interfere }\end{array}$


Circle the ONE number that describes your pain at its WORST in the last week.

$\begin{array}{llllllllccc}0 & 1 & 2 & 3 & 4 & 5 & 6 & 7 & 8 & 9 & 10 \\ \text { No } \\ \text { pain }\end{array}$

Circle the ONE number that describes your pain at its LEAST in the last week.

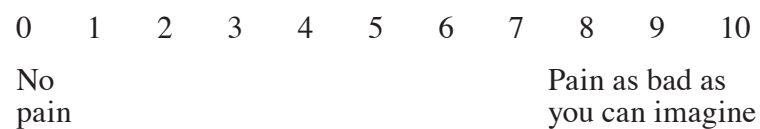

Circle the ONE number that describes your pain at its AVERAGE in the last week.

$\begin{array}{llllllllccc}0 & 1 & 2 & 3 & 4 & 5 & 6 & 7 & 8 & 9 & 10 \\ \text { No } \\ \text { pain }\end{array}$

Circle the ONE number that describes your pain RIGHT NOW.

$\begin{array}{llllllllccc}0 & 1 & 2 & 3 & 4 & 5 & 6 & 7 & 8 & 9 & 10 \\ \text { No } \\ \text { pain }\end{array}$

\section{Appendix 2}

\section{Patient Global Impression of Change (PGIC)}

Choose one of these 7 descriptions that best describes how your symptoms have improved or worsened.

1 - Very much improved

2 - Much improved

3 - Minimally improved

4 - No change

5 - Minimally worse

6 - Much worse

7 - Very much worse

\section{References}

1. Barker FG II, Jannetta PJ, Bissonette DJ, Larkins MV, Jho HD: The long-term outcome of microvascular decompression for trigeminal neuralgia. N Engl J Med 334:1077-1083, 1996

2. Bolton JE: Sensitivity and specificity of outcome measures in patients with neck pain: detecting clinically significant improvement. Spine (Phila Pa 1976) 29:2410-2418, 2004

3. Bromm B: Pain Measurement in Man: Neurophysiological Correlates of Pain. Amsterdam: Elsevier Science Publishers, 1984, pp 13-33

4. Burchiel KJ: A new classification for facial pain. Neurosurgery 53:11641167, 2003

5. Chen HI, Lee JY: The measurement of pain in patients with trigeminal neuralgia. Clin Neurosurg 57:129-133, 2010

6. Cleeland CS, Ryan KM: Pain assessment: global use of the Brief Pain Inventory. Ann Acad Med Singapore 23:129138,1994

7. Copay AG, Subach BR, Glassman SD, Polly DW Jr, Schuler TC: Understanding the minimum clinically important difference: a review of concepts and methods. Spine J 7:541-546, 2007

8. Crosby RD, Kolotkin RL, Williams GR: Defining clinically meaningful change in health-related quality of life. J Clin Epidemiol 56:395-407, 2003

9. Deyo RA, Centor RM: Assessing the responsiveness of func- tional scales to clinical change: an analogy to diagnostic test performance. J Chronic Dis 39:897-906, 1986

10. Faraggi D, Reiser B, Schisterman EF: ROC curve analysis for biomarkers based on pooled assessments. Stat Med 22:25152527, 2003

11. Farrar JT, Berlin JA, Strom BL: Clinically important changes in acute pain outcome measures: a validation study. J Pain Symptom Manage 25:406-411, 2003

12. Farrar JT, Portenoy RK, Berlin JA, Kinman JL, Strom BL: Defining the clinically important difference in pain outcome measures. Pain 88:287-294, 2000

13. Farrar JT, Pritchett YL, Robinson M, Prakash A, Chappell A: The clinical importance of changes in the 0 to 10 numeric rating scale for worst, least, and average pain intensity: analyses of data from clinical trials of duloxetine in pain disorders. J Pain 11:109-118, 2010

14. Farrar JT, Young JP Jr, LaMoreaux L, Werth JL, Poole RM: Clinical importance of changes in chronic pain intensity measured on an 11-point numerical pain rating scale. Pain 94:149-158, 2001

15. Geisser ME, Clauw DJ, Strand V, Gendreau RM, Palmer R, Williams DA: Contributions of change in clinical status parameters to Patient Global Impression of Change (PGIC) scores among persons with fibromyalgia treated with milnacipran. Pain 149:373-378, 2010

16. Grzybowski M, Younger JG: Statistical methodology: III. Receiver operating characteristic (ROC) curves. Acad Emerg Med 4:818-826, 1997

17. Halpern CH, Lang SS, Lee JYK: Fully endoscopic microvascular decompression: our early experience. Minim Invasive Surg 2013:739432, 2013

18. Hanley JA, McNeil BJ: The meaning and use of the area under a receiver operating characteristic (ROC) curve. Radiology 143:29-36, 1982

19. Headache Classification Subcommittee of the International Headache Society: The International Classification of Headache Disorders: 2nd edition. Cephalalgia 24 Suppl 1:9-160

20. Hosmer DW, Lemeshow S: Applied Logistic Regression, ed 2. Hoboken, NJ: John Wiley \& Sons, 2000, p 375

21. Jaeschke R, Singer J, Guyatt GH: Measurement of health status. Ascertaining the minimal clinically important difference. Control Clin Trials 10:407-415, 1989

22. Juniper EF, Guyatt GH, Willan A, Griffith LE: Determining a minimal important change in a disease-specific Quality of Life Questionnaire. J Clin Epidemiol 47:81-87, 1994

23. Lang SS, Chen HI, Lee JYK: Endoscopic microvascular decompression: a stepwise operative technique. ORL J Otorhinolaryngol Relat Spec 74:293-298, 2012

24. Lee JYK, Chen HI, Urban C, Hojat A, Church E, Xie SX, et al: Development of and psychometric testing for the Brief Pain Inventory-Facial in patients with facial pain syndromes. Clinical article. J Neurosurg 113:516-523, 2010

25. Norman GR, Stratford P, Regehr G: Methodological problems in the retrospective computation of responsiveness to change: the lesson of Cronbach. J Clin Epidemiol 50:869879, 1997

26. Reddy VK, Parker SL, Patrawala SA, Lockney DT, Su PF, Mericle RA: Microvascular decompression for classic trigeminal neuralgia: determination of minimum clinically important difference in pain improvement for patient reported outcomes. Neurosurgery 72:749-754, 2013

27. Rogers CL, Shetter AG, Fiedler JA, Smith KA, Han PP, Speiser BL: Gamma knife radiosurgery for trigeminal neuralgia: the initial experience of The Barrow Neurological Institute. Int J Radiat Oncol Biol Phys 47:1013-1019, 2000

28. Ross M: Relation of implicit theories to the construction of personal histories. Psychol Rev 96:341-357, 1989 
29. Salaffi F, Stancati A, Silvestri CA, Ciapetti A, Grassi W: Minimal clinically important changes in chronic musculoskeletal pain intensity measured on a numerical rating scale. Eur J Pain 8:283-291, 2004

30. Schisterman EF, Faraggi D, Reiser B, Hu J: Youden Index and the optimal threshold for markers with mass at zero. Stat Med 27:297-315, 2008

31. Turk DC, Dworkin RH, Allen RR, Bellamy N, Brandenburg $\mathrm{N}$, Carr DB, et al: Core outcome domains for chronic pain clinical trials: IMMPACT recommendations. Pain 106:337345, 2003

32. Turk DC, Rudy TE, Sorkin BA: Neglected topics in chronic pain treatment outcome studies: determination of success. Pain 53:3-16, 1993

33. van der Roer N, Ostelo RWJG, Bekkering GE, van Tulder MW, de Vet HCW: Minimal clinically important change for pain intensity, functional status, and general health status in patients with nonspecific low back pain. Spine (Phila Pa 1976) 31:578-582, 2006

34. Zakrzewska JM, Lopez BC: Quality of reporting in evaluations of surgical treatment of trigeminal neuralgia: recom- mendations for future reports. Neurosurgery 53:110-122, 2003

\section{Author Contributions}

Conception and design: Lee, Sandhu, Halpern. Acquisition of data: Sandhu, Vakhshori, Mirsaeedi-Farahani. Analysis and interpretation of data: Lee, Sandhu, Halpern, Vakhshori, Farrar. Drafting the article: Lee, Sandhu, Halpern, Farrar. Critically revising the article: all authors. Reviewed submitted version of manuscript: all authors. Approved the final version of the manuscript on behalf of all authors: Lee. Statistical analysis: Lee, Sandhu, Halpern. Administrative/technical/material support: Sandhu. Study supervision: Lee, Sandhu, Halpern.

\section{Correspondence}

John Y. K. Lee, Department of Neurosurgery, University of Pennsylvania, 235 South Eighth St., Philadelphia, PA 19106. email: leejohn@uphs.upenn.edu. 